\title{
Health Disparities: A Life Course Health Development Perspective and Future Research Directions
}

\author{
Kandyce Larson, Shirley A. Russ, Robert S. Kahn, \\ Glenn Flores, Elizabeth Goodman, Tina L. Cheng, \\ and Neal Halfon
}

\section{Introduction}

Health disparities on the basis of social class and race/ethnicity are apparent across a broad spectrum of health conditions at all stages of development from birth through older age (Tanner 2015). Historically, much of the research on health disparities has been conducted using cross-sectional data, often in adulthood, with the search for explanatory factors focused on current circumstances that might contribute to health status differentials between individuals in different social groups. Life course theories that seek to explain the developmental origins of and lifespan contributors to health status disparities have gained popularity in recent years, and life courseoriented research has proliferated across diverse disciplines spanning the social, health, and biological sciences (Burton-Jeangros et al. 2015; Kuh and Ben-Shlomo 2004). The goals of this chapter are to describe how an integrated life course health development framework can be applied to better understand health disparities, review examples of the types of life courseoriented research completed to date, identify
K. Larson, $\operatorname{PhD}(\bowtie)$

Department of Research, American Academy of Pediatrics, 141 Northwest Point Boulevard, Elk Grove Village, IL 60007, USA

e-mail: kalarson@aap.org

\section{S.A. Russ, MD, MPH}

UCLA Center for Healthier Children, Families, and Communities, Department of Pediatrics, David Geffen School of Medicine, UCLA, Los Angeles, CA, USA

R.S. Kahn, MD, MPH

Division of General and Community Pediatrics, Cincinnati Children's Hospital Medical Center, University of Cincinnati College of Medicine, Cincinnati, $\mathrm{OH}$, USA

G. Flores, MD, FAAP

Medica Research Institute, Division of Health Policy and Management, University of Minnesota School of Public Health, Minneapolis, MN, USA
E. Goodman, MD

Division of General Academic Pediatrics, Mass General Hospital for Children, Department of Pediatrics, Harvard Medical School, Boston, MA, USA

T.L. Cheng, MD, MPH

Department of Pediatrics, Johns Hopkins University School of Medicine, Baltimore, MD, USA

N. Halfon, MD, MPH

Department of Pediatrics, David Geffen School of Medicine, UCLA, Los Angeles, CA, USA

Department of Health Policy and Management, Fielding School of Public Health, UCLA,

Los Angeles, CA, USA

Department of Public Policy, Luskin School of Public Affairs, UCLA, Los Angeles, CA, USA

Center for Healthier Children, Families, and Communities, UCLA, Los Angeles, CA, USA 
gaps in knowledge, and provide recommendations for future research aimed at eliminating health disparities in childhood and through the life course. For the purpose of this chapter, the term "health disparities" is used to refer to differences in health status between members in certain population groups with a primary focus on socioeconomic status (SES) and race/ethnicity.

\section{Life Course Health Development Framework}

Several articles discuss life course issues applied to health disparities (Alwin and Wray 2005; Braveman and Barclay 2009; DC Baltimore Research Center on Child Health Disparities Writing Group 2009; Wadsworth 1997), but principles, terminologies, and definitions of what constitutes a life course perspective vary across disciplines. Emerging from a synthesis of research across diverse disciplines such as life course sociology, lifespan developmental psychology, neuroscience, chronic disease epidemiology, and epigenetics, the life course health development (LCHD) framework provides an integrated account of the dynamic processes whereby diverse social and environmental exposures interact with biological forces from preconception onward to shape health development trajectories (Halfon and Hochstein 2002; Halfon et al. 2014a). Herein we briefly review how the following basic LCHD principles can be applied to health disparities: (1) health is an emergent developmental capacity of individuals that develops continuously across the lifespan; (2) health development is a dynamic nonlinear process occurring in multiple dimensions and at multiple levels and phases; and (3) health development is sensitive to the timing and social structuring of environmental exposures.

Health is an emergent developmental capacity that develops continuously across the lifespan:

Central to the LCHD theory is the notion that health follows a dynamic trajectory of development that begins before birth and extends through the full lifespan. Drawing on positive notions of health like the Ottawa Charter's definition as a capacity that enables the individual to achieve life's goals, health is conceived as an emergent set of capacities that develops across the life course as a result of transactions between the organism and its internal and external environments (National Research Council \& Institute of Medicine 2004). Health develops continuously and progresses through phases beginning with the early formation of the organism in the preconception and prenatal periods, followed by the optimization of health and developmental capacity in early childhood through young adulthood, maintenance of health capacity in middle adulthood, and management of decline in health in late adulthood. At any given time an individual may be moving toward greater or lesser degrees of health.

Applied to health disparities, the LCHD framework underscores the importance of examining how individuals in different SES and racial/ ethnic groups may manifest varying trajectories of health development and highlights the need to examine not only differences in ill health and disease, but also subclinical health states, health capacity or potential, and a range of health outcomes that vary from poor to very positive.

Health development is a dynamic nonlinear process occurring in multiple dimensions and at multiple levels and phases:

The LCHD framework incorporates an ecological (Bronfenbrenner 1992, 2005) and relational developmental systems perspective (Overton 2013a, b, 2014) to inform how health development is influenced by complex interactions among risk and protective factors across multiple domains and levels of organization over extended time frames. Physical, biochemical, psychological, social, and cultural domains dynamically interact to shape the health development process. The processes of health development also occur at multiple interacting levels of organization. Factors at the social and geopolitical level (e.g., social policy supports for healthy child development, institutional racism) influence factors at the community, family, and individual levels which, in turn, influence health development at the organ, cellular, molecular, and genomic levels. Processes at the molecular/ 
genomic level can dynamically interact with each other, as well as with factors at the social and geopolitical level or anywhere in between. The search for explanatory factors for disparities in health associated with SES and race/ethnicity has typically focused on downstream factors such as individual health behaviors and access to health care. By incorporating an ecological perspective, the LCHD framework broadens the focus of potential explanatory factors to also include more upstream determinants like social policy- and community-level factors.

From a relational developmental systems perspective, it is not surprising that health risk and protective factors tend to cluster together for individuals from disadvantaged backgrounds. The relations among risk factors, protective factors, and health outcomes are complex, dynamic, interactive, and nonlinear with exponential effects and tipping points. In contrast to traditional epidemiologic approaches that emphasize single risk factors and single health outcomes, a given risk or protective factor or combination of factors can lead to multiple different health outcomes (multifinality), and there are multiple different pathways to the same outcome (equifinality). Social determinants may be nonspecific such that, for example, poverty and disadvantage elicit exposure to stressors that result in multiple suboptimal outcomes across the physical, cognitive, and socioemotional domains. From an LCHD system view, it may not be possible to isolate the effects of any given risk or protective factor from that of others because their influence may be interactive and dependent on the array of other influences present in the system. Relationships among variables also follow dynamic patterns like feedback loops. For example, health may impact SES and SES may in turn impact health.

Health development is sensitive to the timing and social structuring of environmental exposures:

Although exposures at all points in the life course impact health, those early in life are thought to be particularly important, due to heightened biological plasticity and behavioral sensitivity. This allows early experiences and events to condition biological and behavioral response patterns in ways that can be adaptive or maladaptive, influencing health development pathways into adulthood. The early social environment can impact health development over time through biological conditioning, pathway, and cumulative mechanisms (Hertzman and Boyce 2010).

Biological conditioning occurs when experiences early in life quite literally get "under the skin," altering neural, endocrine, immunologic, and even genetic systems that in turn impact the course of human development (Hanson and Gluckman 2014; Hertzman 2012; Hertzman and Boyce 2010). For example, exposure to specific antigens in utero will stimulate specific immune responses, and exposure to maternal depression during specific developmental phases can lead to alterations in the responsiveness of a child's hypothalamic-pituitary-adrenal (HPA) axis as measured by cortisol output and effects. Although the focus has typically centered on the prenatal and early childhood phases, sensitive periods of heightened biological vulnerability to socially patterned exposures also occur at other stages including preconception and adolescence.

Pathway models represent how exposures at one point in the life course impact exposures at another point which in turn impact health. Cumulative models emphasize the additive impact of risk and protective health exposures over time for individuals in different social groups. Chains of risk models combine elements of both to detail how individuals in different social groups can experience varied social, psychosocial, and biological chains of risk and protection that take a cumulative toll on health development across the life course. These models suggest how patterns of socially arrayed and interacting exposures can channel biological and behavioral adaptations in mutually reinforcing ways. For example, a child growing up in a lowincome family might experience less-thanoptimal language exposure and a low-quality family childcare experience, where he or she watches television or videos all day. That same child is more likely to attend a low-performing elementary school that is not responsive to his or 
her already depleted developmental potential. As a consequence of this child's disadvantage, not only do they not arrive at school ready to learn, but a lower trajectory is further reinforced by a low-performing school that does not have the capacity to boost this child into a more promising educational pathway and subsequent life course health development trajectory.

In addition to contributing to health disparity development across a lifetime, biological conditioning, pathway, and cumulative mechanisms can influence the transfer of differential health potential across generations. For example, a mother from lower SES origins may incur an accumulation of health-damaging exposures over a lifetime which increases her risk for gestational diabetes, and this in turn, along with differential feeding and health practices associated with SES, may heighten risk for offspring obesity. Despite the LCHD emphasis on the importance of timing and the social structuring of environmental exposures, the framework also details the potential for developmental plasticity and resilience at all phases of development, thus suggesting a need for research examining protective forces leading to more optimal health outcomes for those from disadvantaged social groups.

\section{Brief Overview of Research on Health Disparities from an LCHD Perspective}

Life course research that is relevant to understanding SES and racial/ethnic health disparities has expanded rapidly across a diverse set of disciplines. A full review of this literature is beyond the scope of this chapter, but the following examples demonstrate the types of research completed to date that begin to show the value of an LCHD perspective applied to health disparities. In the sections that follow, we briefly review research related to life course social disadvantage and adult health, the biology of social adversity, the intergenerational transfer of health disparities, and early intervention studies.

\subsection{Life Course Social Disadvantage and Adult Health}

A wide variety of international epidemiological investigations from studies spanning multiple decades have established associations between early life social disadvantage and adult health. Low childhood SES shows an independent association with a range of adverse adult health outcomes, including obesity, diabetes, cardiovascular disease, respiratory illness, cognitive decline, functional limitation, shortened telomere length - an indicator of early aging - and early mortality (Johnson and Schoeni 2011; Kamphuis et al. 2012; Packard et al. 2011; Pudrovska et al. 2014; Robertson et al. 2012; Strand et al. 2011). Studies with multiple indicators of SES at different points across the life course generally find that the risk of ill health and disease increases with more continuous lifetime exposure to lower socioeconomic status (Gustafsson et al. 2011; Luo and Waite 2005). Similarly, research examining racial/ethnic disparities in functional limitation, chronic disease onset, and early mortality demonstrates the important role of life course SES in explaining a portion of the black-white gaps in health (Haas and Rohlfsen 2010; Pais 2014; Warner and Hayward 2006). Studies in early adulthood have shown diverging trajectories of general health, body mass index, blood pressure, and respiratory function for those with different SES and racial/ethnic origins (Albrecht and Gordon-Larsen 2013; Jackson et al. 2004; Janicki-Deverts et al. 2012; Sacker et al. 2011).

The complex associations between early social disadvantage and future health states are becoming better understood as research begins to provide plausible pathways for how childhood SES shapes early cognitive, physical, and behavioral development; future educational attainment; and long-term stressful exposures and health risk behaviors that in turn influence health outcomes (Hertzman et al. 2001; Luo and Waite 2005; Schoon et al. 2003; Van de Mheen et al. 1998). Most studies have examined the role of risk factors in producing poorer health outcomes for those in more disadvantaged social groups, but 
some recent studies have examined how protective factors such as maternal warmth in childhood can buffer the effects of early social disadvantage and promote more optimal long-term health trajectories for those from lower SES backgrounds (Chen et al. 2011; Miller et al. 2011).

\subsection{The Biology of Social Adversity}

The underlying biological mechanisms that contribute to health disparities are not clearly delineated, but research suggests possible avenues through exposures known to vary by SES and race/ethnicity, such as early psychosocial stress, maternal nutrition and related preconception health states, and environmental toxicant exposure (Thayer and Kuzawa 2011). A rapidly expanding literature on epigenetics has provided clues to potentially plausible mechanisms that might underlie biological conditioning by demonstrating how gene expression can be modified in response to environmental cues (Cole 2014; Hanson and Gluckman 2014; Meaney 2010; Meloni 2014; Misteli 2013). Although much of the early literature on biological conditioning came from animal studies, several recent epidemiological investigations have examined biomarkers of stress and epigenetic processes in human populations.

Possible stress-related pathways between social adversity and health have received a great deal of attention in the literature. Adverse childhood experiences appear to be associated with enduring changes in the nervous, endocrine, and immune systems (Danese and McEwen 2012). Research has shown that childhood exposure to stressors such as abuse and neglect, maternal depression, and socioeconomic disadvantage shows both short- and long-term associations with future elevated HPA axis and autonomic nervous system reactivity, immune-inflammatory dysregulation, metabolic disturbance, and alterations in the structure and function of the regions of the brain that control emotions, attention, learning, and memory (Brand et al. 2010; Dougherty et al. 2013; Goodman et al. 2005,
2007; Miller and Chen 2007, 2013; Pietras and Goodman 2013; Sheridan et al. 2012). Studies that have examined epigenetic marks and DNA methylation patterns of individuals exposed to these types of stressors in childhood suggest a possible role for epigenetic processes in producing long-term alterations in physiological functioning (Anacker et al. 2014; Oberlander et al. 2008; Perroud et al. 2014; Romens et al. 2014; Tehranifar et al. 2013). Over time, alterations that contribute to repeated chronic activation of stress-responsive systems can lead to what has been termed "allostatic load" or cumulative wear and tear across a variety of physiological systems, thereby increasing susceptibility to many different types of chronic conditions at different stages of life such as asthma, learning disorders, psychiatric disorders, stroke, diabetes, and cardiovascular disease (Danese and McEwen 2012; Seeman et al. 2010).

Early research on nutrition-related biological conditioning examined long-term linkages between low birth weight and future metabolic and cardiovascular disease risk that were thought to be attributable to the impact of undernutrition in utero on blood pressure regulation, cholesterol metabolism, and glycemic control, as well as the mismatch between in utero nutrient scarcity and calorie-dense environments after birth (Barker et al. 1993; Hales and Barker 2001). This work has expanded to investigate the role of a wide variety of specific micronutrients at distinctive phases in preconception, lifetime nutrient stores, and maternal metabolic and cardiovascular functioning and disruptions in the maternal-fetal interface, including placental function, uteroplacental blood flow, and fetal metabolism (Gillman 2005; Shapira 2008). For example, maternal gestational diabetes, which is more common in low-income overweight and obese women, is associated with fetal hyperinsulinemia and a higher risk of obesity and impaired glucose tolerance in the growing child (Gillman et al. 2003). Environmental toxicant exposures include a wide range of factors such as smoking and air pollution. Whereas most research has focused on the biological impact of prenatal and postnatal exposures, new studies are beginning to show possible transgenerational 
effects through epigenetic changes in the germline connected with smoke and toxicant exposure which provides an argument for the importance of the preconception health states of parents (Curley et al. 2011; Laubenthal et al. 2012).

\subsection{Intergenerational Health Disparities}

A growing line of epidemiologic research examines the early emergence of health disparities in childhood and the possible role of intergenerational mechanisms in contributing to early health disparities. Perhaps most suggestive of a role for intergenerational mechanisms is the fact that beginning at birth, large disparities on the basis of SES and race/ethnicity are already apparent for child outcomes like prematurity and birth weight (Coley and Aronson 2013; Gray et al. 2014). Studies that have examined associations of mother's SES in her own childhood suggest long-term linkages with her future prenatal health, health practices, and reproductive outcomes (Astone et al. 2007; Gavin et al. 2011, 2012).

In 2013, the preterm birthrate for AfricanAmericans was $16 \%$, compared with $10 \%$ for white women, with a near doubling of risk for low birth weight (13\% vs. $7 \%$ ) and near tripling of risk for very low birth weight (2.9\% vs. $1.1 \%$ ) (Martin et al. 2015). Although a low-income African-American woman who delivers a child 3 months prematurely might traditionally be assessed in terms of her delayed access to prenatal care, through a life course health development perspective, we would also consider her lifelong health status, her reproductive conditioning, the impact of experiences such as her own mother's depression during her infancy, perceived racism, and other toxic and stressful experiences that potentially impact the structure and function of her HPA axis.

A well-established literature indicates that the cumulative impact of stress-related weathering might have a major impact on the health of African-American mothers (Geronimus 1996; Geronimus et al. 2006; Holzman et al. 2009; Love et al. 2010). The weathering hypothesis, which is similar to allostatic load theory, proposes that, on average, the health trajectory of AfricanAmerican women may begin to deteriorate early in adulthood as a physical consequence of cumulative socioeconomic disadvantage, stress, and racism. In support of this hypothesis, studies show a near fourfold increase in the risk of low birth weight and very low birth weight with increasing age for African-American women but not for white women (Geronimus 1996). Racial/ethnic disparities in measures of women's health, such as obesity, high blood pressure, high cholesterol, and diabetes, also increase with age (Buescher and Mittal 2006; Geronimus et al. 2010; Miranda et al. 2010). Plausible biological pathways between social and environmental stress and birth outcomes include maternal HPA axis functioning, immune-inflammatory response, and vascular function altering uteroplacental flow (Kramer et al. 2011; Kramer and Hogue 2009). Preliminary research examining diverse biomarkers of risk for preterm birth suggests a possible role for proinflammatory pathways for African-American mothers (Brou et al. 2012).

Continuing in early childhood, disparities by SES and race/ethnicity are apparent across a wide range of physical, behavioral, and cognitive measures, and these disparities appear to widen over time as children age (American Academy of Pediatrics Committee on Pediatric Research 2010; Flores et al. 2005; Halle et al. 2009; Larson and Halfon 2009; Martinson et al. 2015). A series of studies examining early child health disparities suggest a possible role for intergenerational transfer of risk through factors like parent SES origins and parent health and health practices. For example, studies have shown a possible contributory role for factors including grandparent social class, maternal psychopathology, maternal stress, and both pre- and postnatal maternal smoking in explaining SES gradients in children's early asthma symptoms (Hafkamp-de Groen et al. 2012; Sternthal et al. 2011; Violato et al. 2009). Early parent health and health practices, including maternal mental health status in particular, have also been associated with SES gradients in children's behavior problems, general health status, and obesity (Kahn et al. 2005; 
Khanam et al. 2009; Propper et al. 2007). For cognitive outcomes, health factors like mother's preconception obesity, breastfeeding, and depression appear to make a small contribution to early gradients by SES along with a wide variety of additional early risk and protective factors (Dearden et al. 2011; Larson et al. 2015).

\subsection{Early Intervention Studies}

A range of studies have examined the short- and long-run impact of early childhood interventions on future health and well-being. For example, early nurse home visiting programs for lowincome families show long-term improvements for children including better intellectual functioning, fewer behavioral problems, fewer preventable injuries, and less risky health behaviors in adolescence (Olds et al. 1998, 2004, 2007). Parenting interventions in pregnancy and the first year have been shown to improve parent relationships, decrease family stress, reduce biomarkers of stress, and improve executive function and school performance of children (Feinberg et al. 2014, 2015).

Whereas the focus has been more on social and educational outcomes, a number of preschool early intervention studies have tracked participant well-being into adulthood. For example, the Ypsilanti Perry Preschool study showed that an intensive multicomponent preschool program with teacher home visits for low-income AfricanAmerican children improved adult educational attainment and literacy scores, employment outcomes, family relationships, and health practices (Schweinhart et al. 2005; Schweinhart and Weikart 1993). Several other educationally focused studies have shown similar results (Campbell et al. 2008; Reynolds et al. 2011). Recent follow-up studies of participants in the Chicago Preschool study, the Brookline Early Education Project, and the Abecedarian Project have shown healthfocused benefits like more private health insurance coverage, less disability, less depression, better self-rated health, and less cardiovascular and metabolic risk (Campbell et al. 2014; Palfrey et al. 2005; Reynolds et al. 2007). Studies examin- ing neighborhood-level interventions, such as the Moving to Opportunity study, which randomly assigned some low-income families living in high-poverty neighborhoods to receive free housing in more advantaged neighborhoods, have also shown some future improvements in health for participant parents, children, and youth, although results vary by outcome (Leventhal and Dupéré 2011; Ludwig et al. 2013).

Few studies have examined interventions that begin in the preconception period, although one exception is the Magnolia Project, which targets at-risk African-American women of childbearing age who are not yet pregnant and provides multicomponent outreach services, risk reduction, well-woman care, health education, stress resilience services, and community development. Early evaluations demonstrate successful risk reduction with improved family planning and reduced STDs for program participants and marginally statistically significant improvements in low birth weight (Biermann et al. 2006; Livingood et al. 2010). Additional research is needed to determine the impact of social and health interventions beginning before pregnancy.

\section{$4 \quad$ Research Limitations and Gaps in Knowledge and Translation to Policy and Practice}

Despite rapid advances in research relevant to understanding health disparities from a life course perspective, there are still many limitations and gaps in the knowledge base and the translation to policy and practice. In this section, we provide an overview of some of the important research challenges.

\subsection{Existing Data Sets}

Much of the developmental and life course research relevant to understanding health disparities has been conducted on data sources not specifically designed for this purpose. Pregnancy and prepregnancy longitudinal data sources are 
limited, especially in the USA. Few studies contain three-generational data spanning from grandparent to parent to child health. Research on the early origins of racial/ethnic disparities in health has been particularly hindered by the limited availability of pregnancy and prepregnancy cohort studies in the USA, and studies often exclude important groups and subgroups, such as American Indians/Alaska Natives, multiracial individuals, Mexican Americans, or Puerto Ricans, due to sample size issues. There is also a growing immigrant population who are underrepresented in data sets. Despite the many strengths of US longitudinal studies, such as the Early Childhood Longitudinal Study, the National Longitudinal Survey of Youth, and the Panel Study of Income Dynamics, these surveys do not primarily focus on health and have fairly limited direct physical health assessment. Much of the existing knowledge on the early biological origins of future health problems comes from animal studies, in part owing to the lack of available data sources containing both social and biological measures needed to delineate the complex pathways and interactions leading to health disparities.

\subsection{Concepts and Measurement}

Understanding health disparities requires having well-defined measures of SES; race/ethnicity; potential explanatory factors across the biological, psychological, social, and cultural domains; and health outcomes (American Academy of Pediatrics Committee on Pediatric Research 2015). Measurement complexity begins with SES and race/ethnicity. Measures of SES are often chosen based on data availability instead of conceptual concerns. Standard approaches to categorizing race/ethnicity may need reconsideration with growing diversity and racial mixing, and many have noted the limitation that selfreported race/ethnicity should not be used as a proxy for genetic ancestry in biological studies (Eisenhower et al. 2014; Mersha and Abebe 2015). Several critical life course concepts such as stress, weathering, and allostatic load lack consistent measurement approaches, and little is currently known about how these concepts might best be operationalized at different stages of life including childhood and adolescence. Much work remains to develop adequate biomarkers for health and disease that can be applied consistently across studies. In the area of stress research, for example, short-term fluctuations in cortisol levels can complicate research findings, and hair cortisol, telomere length, and multifactorial approaches to the choice of biomarkers have been suggested (McEwen 2015; Sauvé et al. 2007). Social contributors to health disparities like discrimination, acculturation, or immigration stress also lack standardized measurement approaches. For health outcome measurement, limited measures of positive health states are available at different life stages. Measures are often not available in diverse languages and have not been tested for equivalence across socioeconomically and culturally diverse groups.

\subsection{Statistical Methods}

Recent years have seen rapid advancement in the application of sophisticated statistical methods such as longitudinal growth models to examine health status trajectories, multilevel modeling to examine contextual influences on health, and decomposition methodologies to sort through the contribution of multiple risk and protective factors at different life stages to future health status disparities. Despite progress, there are some fundamental limitations with standard statistical approaches that stem from a reductionist approach aimed at isolating the "causal" impact of a given variable. Studies that examine mediators or contributors to health status disparities using standard regression approaches are inherently limited by possible residual confounding and may miss important connections if associations among risk factors, protective factors, and health outcomes are complex, interactive, reciprocal, or nonlinear. New methods of analysis stemming from dynamic systems approaches have the potential to complement more traditional analyses and incorporate many different 
aspects of the complexity inherent in the LCHD framework, but to date there has been limited application to the field of health disparities (Diez Roux 2007, 2011; Speybroeck et al. 2013). Dynamic systems methods include a range of computational approaches that can be used to model dynamic interactions between individuals and their environments, and complex phenomenon including feedback loops and nonlinear relations.

\subsection{LCHD Framework}

Comparing the current state of research on the early origins and development of disparities in health with existing life course frameworks reveals several limitations and gaps in knowledge. While the LCHD framework emphasizes the critical importance of structural and upstream policy- and community-level determinants of health status disparities, most research has focused on more downstream factors, such as health behaviors or health care. With the growing popularity of research on toxic stress, epigenetics, and the role of early pre- or postnatal programming of future health states, some have cautioned that the field should not lose sight of the broader structural forces like racism, environmental inequity, and decaying housing structures that can impact health across the life course (Geronimus 2013). There is also limited research available on resilience and the role of protective factors in promoting positive health trajectories for individuals in disadvantaged social groups. Most studies have investigated poor health and disease outcomes rather than functional health trajectories and biomarkers of future health potential. Overall, knowledge of the complex mechanisms whereby biological, environmental, social, and behavioral factors interact over extended time frames to produce disparities in population health is limited, and many critical questions remain unanswered, such as the ongoing debate about the importance of early vs. later events and the timing and mutability of critical or sensitive periods in human development.

\subsection{Intervention and Translation}

Despite the recent upsurge in research activity on health disparities in the USA, progress toward meeting the US Department of Health and Human Services' Healthy People goals of reducing or eliminating health disparities has been slow, and gaps for socially disadvantaged groups are, in fact, increasing for certain key health indicators such as infant, childhood, and adult mortality (Singh and Kogan 2007; Singh and Siahpush 2002). Indeed, a recent analysis of US data on trends in child health disparities documented that children from ethnic minority families continue to experience multiple disparities in medical and oral health and health care, with most disparities persisting over time and some new disparities arising (Flores and Lin 2013). Currently, few evidence-based practice guidelines are available to address specific health disparities, and there is no fully coordinated national policy effort to address disparities. Although there is a growing trend focusing on translational research to integrate knowledge from basic science studies into practical solutions in the clinical, practice, population health, and policy realms, much of the past research on health disparities has had a greater focus on documenting disparities than providing actionable interventions.

The evidence base on effective health interventions is limited in several ways. Many of the longterm follow-up studies tracking early childhood interventions have primarily been conducted in the field of education and therefore lack a specific focus on health outcomes or on the biological and behavioral adaptive mechanisms that might explain long-term outcomes. Few interventions have been designed to target specific social and health risk and protective factors prior to pregnancy, and we still know very little about the best time to intervene to influence specific health outcomes. Interventions for racial/ethnic health disparities are often not specifically designed to meet the unique needs of individuals in diverse cultural groups, and few studies have examined community-level interventions or the impact of interventions designed to optimize health instead of reverse risk factors. Despite these limitations, a range of early intervention studies demonstrate 
promise for improving future well-being for children in disadvantaged home environments, and yet these have not been implemented in practice on a broad scale in the USA, indicating a need for policy change and a greater focus on scaling up proven strategies in community-based practice.

\section{Recommendations and Considerations for a New Life Course Health Disparities Research Agenda}

Addressing disparities in health in the population at large will require attention to the parental, early childhood, and adolescent antecedents of later inequality in health. New research on health disparities from an LCHD perspective will require transdisciplinary collaboration and training in order to advance unified theoretical concepts and measurement approaches and to further research on the complex interplay between social and biological forces in producing health disparities across lifetimes and generations. Similar collaborative efforts are needed to translate knowledge from basic science studies into interventions, programs, and policies that can optimize long-term health development trajectories for individuals from disadvantaged social groups.

Based on our review of the literature related to LCHD and health disparities, we propose the following as priorities for building a new life course health development research agenda:

\section{Research Priorities}

Development and funding of studies that:

1. Investigate the underlying biological processes that contribute to health disparities in human populations.

2. Examine protective factors, resilience, and positive health outcomes for individuals from disadvantaged backgrounds.

3. Examine parental preconception health and other intergenerational mechanisms that may contribute to early health disparities.

4. Continue to investigate the dynamic multilevel contributors to health status disparities across the life course with a particular emphasis on upstream determinants.

5. Compare the impact of the timing of intervention at various life stages for selected health outcomes.

6. Shift beyond minimizing risk and preventing poor health with interventions aimed at optimizing health and developmental potential.

7. Address barriers to reliable widespread implementation of evidence-based interventions.

8. Use place-based and community-based participatory research methodologies.

9. Develop and test new policies and policy interventions at the local, state, and national levels to reduce health disparities across the life course.

\section{Data and Methods Development Priorities}

1. Shift to focus on longitudinal as opposed to cross-sectional studies.

2. Combine sociodemographic, biologic, and genetic data and link across families.

3. Develop new measures of health and possible contributors to health status disparities validated across different racial/ethnic groups.

4. Adopt a complex systems perspective.

5. Improve training in transdisciplinary research and advanced statistical modeling.

\section{Translational Priorities}

1. Identify existing knowledge that is ripe for translation to practice and policy.

2. Align new basic science research with translational approaches to reducing health disparities.

\section{Challenges and Opportunities for Building} a New Life Course Health Development Research Agenda to Reduce Health Disparities

1. Need for more funding by $\mathrm{NIH}, \mathrm{MCHB}$, and other federal agencies and national foundations for life course-oriented health disparities research.

2. Capitalizing on new momentum, interest, and recognition of the importance of social determinants and toxic stress for health disparities in childhood and across the life course.

Below, we describe these priority areas in greater detail. 


\subsection{Research Priorities}

Development and funding of studies that:

1. Investigate the underlying biological processes that contribute to health disparities in human populations.

Population, regional, and clinic-based studies are needed to examine the underlying biological processes that contribute to health disparities in human populations. Studies should examine biological processes impacting health at all stages including birth outcomes, child and adolescent health, and adult health. Priority research areas include the investigation of novel biomarkers of health and disease for populations that are particularly affected by disparate health outcomes, the contribution of stress and allostatic load to health disparities at various life stages, studies of gene-environment interactions and epigenetic mechanisms of health disparities, identification of genetic susceptibility to disease among minority populations, and studies examining gestational/prenatal physiology and its impact on future health disparities.

2. Examine protective factors, resilience, and positive health outcomes for individuals from disadvantaged backgrounds.

Despite lower economic resources overall, certain racial/ethnic and immigrant groups such as Mexican Americans and blacks born outside the USA show surprisingly good outcomes for certain health indicators like child birth weight and longevity (Buekens et al. 2000; Lariscy et al. 2015; Singh and Hiatt 2006). Likewise, many individuals from lower SES origins manage to overcome the odds and have very good health and wellbeing in adulthood. More research is needed to not only identify individuals with exceptional health resilience, but also to better understand the health development pathways that lead to a more resilient phenotype. Studies that examine the cultural, social, and psychological resources that can lead to thriving and better-than-expected health outcomes for individuals from disadvantaged social groups should receive priority. Examples of recent research in this area include studies showing long-term benefits of maternal warmth, child optimism, and shift-and-persist strategies for future health and well-being of individuals from lower SES origins (Chen et al. 2011, 2012; Khullar et al. 2011; Miller et al. 2011).

3. Examine parental preconception health and other intergenerational mechanisms that may contribute to early health disparities.

The LCHD framework points to the importance of addressing the early manifestations of health disparities and intergenerational transfer of health risk and potential. Studies are needed to examine the mechanisms contributing to disparities in birth outcomes, biomarkers of future health potential, and early childhood health. Priority areas include three-generation studies that examine how social factors from parent's own childhood may influence their future health, well-being, and parenting practices with consequences for offspring health and the role of parental preconception health status. In the biological realm, an important area of research is the role of the placenta as a regulator of the intrauterine environment and programming agent of future health potential and how this ties in with the social, physiological, and nutritional status of the mother. This might include studies that focus on the potential to boost placental functioning so that the placenta might serve as a resilience generator in what might otherwise be a risky intrauterine environment.

4. Continue to investigate the dynamic multilevel contributors to health status disparities across the life course with a particular emphasis on upstream determinants.

Future research should investigate the multilevel contributors to health status disparities over the life course with a particular emphasis on upstream structural factors and neighborhoodlevel determinants. Multilevel studies can help examine the impact of neighborhood-level factors on health disparities by SES and race/ethnicity. 
Also needed are studies that incorporate longitudinal or life course measures of neighborhood and environmental exposures. At the population level, studies are needed to examine the policy, built environment, and social environment exposures that contribute to geographic differentials in rates of health and disease. To the greatest extent possible, research studies that examine lifelong contributors to SES and racial/ethnic health disparities should investigate the importance of timing of key environmental and social exposures.

In addition to empirical studies that are designed to measure the impact of specific environmental exposures on biological conditioning and health, existing data can be used to develop life course health development models using new agent-based and dynamic systems methods. These modeling approaches can represent dynamic interactions and complex multilevel influences over varying time horizons in ways that may be difficult using standard statistical approaches.

5. Compare the impact of the timing of intervention at various life stages for selected health outcomes.

Longitudinal studies are needed that investigate the impact of interventions at various life stages on future health outcomes. The preconception period is an important area for investigation. Many questions remain about the possible benefit of and best timing for interventions in the preconception period for improving birth outcomes and early childhood health in disparity populations. Studies in childhood should examine social interventions designed to alter specific short-term health outcomes (e.g., asthma or early stress reactivity) in at-risk populations as well as more long-term health and well-being outcomes into adulthood. For example, can populationlevel interventions, like teaching young children yoga and other mindfulness techniques, serve to "inoculate" them against elevations in allostatic load due to stressful and chaotic family environments? Questions about the best timing for intervention are important. Cost-effectiveness studies can be used to compare the value of interventions at different life stages. In addition to interventions at the individual level, studies that intervene on the multilevel determinants of health (e.g., neighborhood-level interventions) will also be important.

6. Shift beyond minimizing risk and preventing poor health with interventions aimed at optimizing health and developmental potential.

Most prior intervention studies have been designed to alter risk behaviors in disparity populations. Few have examined if interventions designed to build individual, family, or community strengths can optimize health trajectories. As an example, a recent study showed that a psychosocial intervention focused on building family strengths and youth competencies was successful in improving biomarkers of health in early adulthood for African-American youth in lower SES families (Miller et al. 2014). To date, we know very little about the potential of interventions that seek to promote optimal health, nutrition, fitness, parenting, and social, psychological, and community resources in health disparity populations. Intervention studies to address the SES gradient in health will also need to focus on optimizing health across the full SES spectrum, including not just low but also middle SES groups. Prior studies have often focused on the problems of poverty and marginal risk without adequate attention given to individuals in more middle-income groups, who also exhibit suboptimal health outcomes and could benefit from interventions designed to boost their health and developmental potential.

7. Address barriers to reliable widespread implementation of evidence-based interventions.

Some evidence-based interventions for improving health and well-being exist but have not yet been implemented in community-based practice on a broad scale. Some existing health interventions have not yet been tested for specific cultural groups such as Native American populations. Dissemination and implementation 
research is needed to help spread knowledge about existing evidence-based interventions, adapt interventions for use with specific cultural or regional groups, and test the effectiveness and cost-efficiency of different interventions in community and practice settings.

8. Use place-based and community-based participatory research methodologies.

Community-based participatory research involving collaboration and partnership between community leaders, residents, and academic researchers can be used to help design interventions that are responsive to local needs and promote policy advocacy in disadvantaged neighborhoods. Recently, many place-based efforts have taken a life course approach in attempt to improve cradle-to-career trajectories with attention paid to what works in different kinds of communities and microenvironments. Community-based researchers in Canada have used a new set of measures including the Early Development Instrument (administered from ages 4-6 years) and the Middle Development Instrument (administered at ages 9-11 years) to collect developmentally and dimensionally consistent measures of health development (Janus and Offord 2007; Schonert-Reichl et al. 2013). This life course-oriented population data collection can be used to map and track health and well-being at different developmental stages, and to engage community members in identifying early development outcomes and how they relate with local community services and risk and protective factors, and in turn developing action strategies for systems- and community-level improvements.

9. Develop and test new policies and policy interventions at the local, state, and national levels to reduce health disparities across the life course.

Translational research is needed to transform knowledge from basic science research into new policies designed to reduce health disparities through the life course. As new social and health policies are devised, research will need to monitor impact and outcomes. For new policy development, computer simulation studies provide an important and, to date, underutilized methodology that policymakers can use to test the likely outcomes of policy changes to address the more upstream determinants of health (e.g., changes in income or education) and test what-if scenarios about the likely impact of alternative early intervention strategies targeting different early risk and protective factors for future health outcomes.

\subsection{Data and Methods Development Priorities}

1. Shift to focus on longitudinal as opposed to cross-sectional studies.

The USA should invest in longitudinal studies that start prior to conception and continue through the life course. Ideally, these longitudinal studies should also collect data on the subsequent generation of children. Despite the difficulties implementing a large-scale study like the US National Children's Study, efforts must continue to investigate new methodologies to make a population-based cohort study like this possible, and smaller-scale regional studies collecting social and biological data on critical life course topics should also receive priority. Existing crosssectional data sets, such as the National Health and Nutritional Examination Surveys (NHANES) and National Survey of Children's Health (NSCH), could be enhanced by adding longitudinal components, linkages with vital statistics and other available data sources, and retrospective measures of parent's life course health, socioeconomic status, perceived racism, and risk and protective exposures. Ongoing longitudinal studies, such as the Early Childhood Longitudinal Study (ECLS), the National Longitudinal Survey of Youth (NLSY), and Panel Study of Income Dynamics, could be altered to include better health measures. Where possible, researchers should also explore innovative options for expanding and cross-linking data contained in sources like electronic health records. 
2. Combine sociodemographic, biologic, and genetic data and link across families.

Longitudinal and cross-generational studies are needed that integrate sociodemographic, biologic, and genetic data. Ongoing and future epidemiologic studies used to investigate health disparities should be examined for opportunities to add biological and genetic data that might contribute to our understanding of life course processes. For example, new studies to investigate social disparities in preterm birth and early childhood health outcomes could add biological information such as maternal blood, DNA, urine, and placenta samples and fetal amniotic fluid and cord blood samples. Likewise, new biorepositories designed to study specific health conditions and built with connections to clinical and questionnaire or epidemiologic data may provide useful opportunities for future health disparities research.

3. Develop new measures of health and possible contributors to health status disparities validated across different racial/ethnic groups.

At present, there are few valid and reliable measures of health not measuring disease, disability, or dysfunction. New measures of health in childhood, adolescence, and adulthood are needed that can be used to study functional health trajectories and positive health outcomes. This will require better conceptualization of health and health development from a measurement implementation standpoint and creation of multimodal health development profiles that include self/parent report, clinical measures, and biomarkers. Research designed to develop standardized measures of critical life course concepts like stress, weathering, and allostatic load at different life stages should also have priority. New measures should be validated for use across different cultural groups.

\section{Adopt a complex systems perspective.}

Complex systems approaches are gaining popularity in public health. Systems approaches can be used to investigate complex phenomenon including feedback loops, nonlinear dynamics, and macro-level patterns that emerge from the interactions of factors at different levels of organization. Applied to health disparities, complex systems approaches may help broaden our understanding of processes like the reciprocal relations among genes and environments across the life course, feedback mechanisms between health and social standing over time, dynamic interactions between people and places in producing health disparities, and the long-term consequences of intervening on structural determinants of health such as early childhood educational opportunities (Diez Roux 2011).

5. Improve training in transdisciplinary research and advanced statistical modeling.

Advancing life course-focused research on health disparities will require collaboration among researchers from many different specialties and fields of study. Traditional academic training has been discipline specific, but new modes of training are needed to provide exposure to different research methods used across diverse fields of study. Applied researchers will need advanced training in the interpretation and use of sophisticated statistical methods ranging from longitudinal growth modeling to dynamic systems approaches. Social scientists will need to incorporate knowledge of concepts and methods traditionally used in the biological sciences and vice versa.

\subsection{Translational Priorities}

1. Identify existing knowledge that is ripe for translation to practice and policy.

Application of existing knowledge from life course-oriented health disparities research to practice and policy is still in the early stages of development. Efforts are needed to identify existing knowledge that is ready for translation into concrete practice guidelines, programs, and policies aimed at alleviating disparities in health in 
childhood and across the life course. For example, life course-oriented research focused on optimizing health development could be used to redesign the health-care system with a greater emphasis on promoting optimal health throughout the life course, from birth through death, instead of focusing on disease management (Halfon et al. 2014b, c). Continued efforts are needed to identify ways in which life course research on health disparities can be integrated into medical, social welfare, education, and public health practice and social and health policies at the local, state, and national levels.

2. Align new basic science research with translational approaches to reducing health disparities.

Historically, research on health disparities has often been conducted in isolated academic institutions without primary attention to how the knowledge gained from basic science studies might be applied in practice or policy. New modes of research involving transdisciplinary collaboration, academic and community partnerships, and new translational research science centers that conduct studies across the continuum from basic science discovery to their application in clinical, practice, and policy settings may help ensure that new discoveries are translated into concrete and practical solutions to promote health for disadvantaged populations.

\subsection{Challenges and Opportunities for Building a New Life Course Health Development Research Agenda to Reduce Health Disparities}

1. Need for more funding by the National Institutes of Health (NIH), Maternal and Child Health Bureau (MCHB), and other federal agencies and national foundations for life course-oriented health disparities research.

Funding declines and tight competition for federal research grants offer a challenge to mov- ing forward in the many areas needed to advance life course-oriented health disparities research. More funding by NIH, MCHB, and other federal agencies and national foundations is needed for life course-oriented health disparities research with a special emphasis on intervention and translational research designed to reduce health disparities in childhood and through the life course. The LCHD framework emphasizes the importance of addressing disparities from preconception onward; understanding that early exposure to multiple stresses may produce biological changes that are difficult, if not impossible, to eradicate later; and acknowledging that adults who experienced the most extreme disparities as young children are likely to develop the worst health in adulthood and require the most expensive interventions. Life course-oriented health disparities research provides an opportunity for large potential savings associated with the development of strategies to intervene early in optimizing human health.

2. Capitalizing on new momentum, interest, and recognition of the importance of social determinants and toxic stress for health disparities in childhood and across the life course.

Despite challenges, interest in life courseoriented health disparities research has gained rapid popularity in recent years. For example, interest in research on the lifelong health consequences of early adversity has rapidly spread and is currently being translated to changes in medical, public health, education, and child welfare practice including the development and expansion of new trauma-informed systems of care. Several states now track and monitor rates of adverse childhood exposures. Just over a decade ago, life course models were relatively marginal in the Maternal and Child Health (MCH) field but are now foundational in guiding $\mathrm{MCH}$ research, practice, and policy (Lu 2014). Within pediatrics, attention to poverty and the social determinants of children's health and development has also grown in response to increasing rates of US family poverty. The emerging research on poverty, toxic 
stress, and epigenetics has been used to frame new American Academy of Pediatrics (AAP) recommendations concerning screening for early adversity and social risk at primary care visits and building pediatric connections with social and educational services in the community to help promote optimal health and development for all children (American Academy of Pediatrics Committee on Psychosocial Aspects of Child and Family Health, Committee on Early Childhood, Adoption, and Dependent Care, \& Section on Developmental and Behavioral Pediatrics 2012). In recent years, both the AAP and the Academic Pediatric Association have placed poverty and child health as a top policy focus.

This growth in attention to social determinants and life course health is encouraging. Research innovation and enhanced support for translational science approaches will be needed to devise and implement practical solutions to address life course health disparities in practice and community settings.

\section{Conclusions}

Although researchers, policymakers, and clinicians have recognized the existence of health disparities for decades, the importance of social, developmental, and health inequalities in the early years as contributors to lifelong differences in health status has only recently been understood. Attempts to address health disparities in the US population that do not include a strong focus on the early years are, at best, misguided and, at worst, likely to fail. At the national level, difficult conversations are needed to address research priorities and strategies for targeting social inequalities. At the same time, life course health development models suggest that there may be new solutions to long-standing problems. Rather than ever-increasing spending on expensive mid- and late-life therapeutic interventions, many of the answers to persistent disparities in health outcomes could lie in better social conditions and health development services for young children.

\section{References}

Albrecht, S. S., \& Gordon-Larsen, P. (2013). Ethnic differences in body mass index trajectories from adolescence to adulthood: A focus on Hispanic and Asian subgroups in the United States. PLOS ONE, 8(9), e72983. doi:10.1371/journal.pone.0072983.

Alwin, D. F., \& Wray, L. A. (2005). A life-span developmental perspective on social status and health. The Journals of Gerontology Series B: Psychological Sciences and Social Sciences, 60(2), S7-S14. doi:10.1093/geronb/60.Special_Issue_2.S7.

American Academy of Pediatrics Committee on Pediatric Research. (2010). Technical report - racial and ethnic disparities in the health and health care of children. Pediatrics, 125(4), e979-e1020. doi:10.1542/ peds.2010-0188.

American Academy of Pediatrics Committee on Pediatric Research. (2015). Race, ethnicity, and socioeconomic status in research on child health. Pediatrics, 135(1), e225-e237. doi:10.1542/peds.2014-3109.

American Academy of Pediatrics Committee on Psychosocial Aspects of Child and Family Health, Committee on Early Childhood, Adoption, and Dependent Care, \& Section on Developmental and Behavioral Pediatrics. (2012). Early childhood adversity, toxic stress, and the role of the pediatrician: Translating developmental science into lifelong health. Pediatrics, 129(1), e224-e231. doi:10.1542/ peds.2011-2662.

Anacker, C., O’Donnell, K. J., \& Meaney, M. J. (2014). Early life adversity and the epigenetic programming of hypothalamic-pituitary-adrenal function. Dialogues in Clinical Neuroscience, 16(3), 321-333.

Astone, N. M., Misra, D., \& Lynch, C. (2007). The effect of maternal socio-economic status throughout the lifespan on infant birthweight. Paediatric and Perinatal Epidemiology, 21(4), 310-318. doi:10.1111/j.1365-3016.2007.00821.x.

Barker, D. J. P., Godfrey, K. M., Gluckman, P. D., Harding, J. E., Owens, J. A., \& Robinson, J. S. (1993). Fetal nutrition and cardiovascular disease in adult life. The Lancet, 341(8850), 938-941. doi:10.1016/0140-6736(93)91224-A.

Biermann, J., Dunlop, A. L., Brady, C., Dubin, C., \& Brann, A. (2006). Promising practices in preconception care for women at risk for poor health and pregnancy outcomes. Maternal and Child Health Journal, 10(1), 21-28. doi:10.1007/s10995-006-0097-8.

Brand, S. R., Brennan, P. A., Newport, D. J., Smith, A. K., Weiss, T., \& Stowe, Z. N. (2010). The impact of maternal childhood abuse on maternal and infant HPA axis function in the postpartum period. Psychoneuroendocrinology, 35(5), 686-693. doi:10.1016/j.psyneuen.2009.10.009.

Braveman, P., \& Barclay, C. (2009). Health disparities beginning in childhood: A life-course perspective. Pediatrics, 124, S163-S175. doi:10.1542/ peds.2009-1100D. 
Bronfenbrenner, U. (1992). Ecological systems theory. In R. Vasta (Ed.), Six theories of child development: Revised formulations and current issues (pp. 187249). London: Jessica Kingsley Publishers.

Bronfenbrenner, U. (2005). Making human beings human: Bioecological perspectives on human development. Thousand Oaks: Sage.

Brou, L., Almli, L., Pearce, B., Bhat, G., Drobek, C., Fortunato, S., \& Menon, R. (2012). Dysregulated biomarkers induce distinct pathways in preterm birth. BJOG: An International Journal of Obstetrics \& Gynaecology, 119(4), 458-473. doi:10.1111/j.1471-0528.2011.03266.x.

Buekens, P., Notzon, F., Kotelchuck, M., \& Wilcox, A. (2000). Why do Mexican Americans give birth to few low birth-weight infants? American Journal of Epidemiology, 152(4), 347-351. doi:10.1093/aje/ 152.4.347.

Buescher, P. A., \& Mittal, M. (2006). Racial disparities in birth outcomes increase with maternal age: Recent data from North Carolina. North Carolina Medical Journal, 67(1), 16-20.

Burton-Jeangros, C., Cullati, S., Sacker, A., \& Blane, D. (Eds.). (2015). A life course perspective on health trajectories and transitions. New York: Springer.

Campbell, F. A., Wasik, B. H., Pungello, E., Burchinal, M., Barbarin, O., Kainz, K., et al. (2008). Young adult outcomes of the Abecedarian and CARE early childhood educational interventions. Early Childhood Research Quarterly, 23(4), 452-466. doi:10.1016/j. ecresq.2008.03.003.

Campbell, F. A., Conti, G., Heckman, J. J., Moon, S. H., Pinto, R., Pungello, E., \& Pan, Y. (2014). Early childhood investments substantially boost adult health. Science, 343(6178), 1478-1485. doi:10.1126/science.1248429.

Chen, E., Miller, G. E., Kobor, M. S., \& Cole, S. W. (2011). Maternal warmth buffers the effects of low early-life socioeconomic status on pro-inflammatory signaling in adulthood. Molecular Psychiatry, 16(7), 729-737. doi:10.1038/mp.2010.53.

Chen, E., Miller, G. E., Lachman, M. E., Gruenewald, T. L., \& Seeman, T. E. (2012). Protective factors for adults from low-childhood socioeconomic circumstances: The benefits of shift-and-persist for allostatic load. Psychosomatic Medicine, 74(2), 178-186. doi:10.1097/PSY.0b013e31824206fd.

Cole, S. W. (2014). Human social genomics. PLOS Genetics, 10(8), e1004601. doi:10.1371/journal. pgen. 1004601 .

Coley, S. L., \& Aronson, R. E. (2013). Exploring birth outcome disparities and the impact of prenatal care utilization among North Carolina teen mothers. Women's Health Issues, 23(5), e287-e294. doi:10.1016/j. whi.2013.06.004.

Curley, J. P., Mashoodh, R., \& Champagne, F. A. (2011). Epigenetics and the origins of paternal effects. Hormones and Behavior, 59(3), 306-314. doi:10.1016/j.yhbeh.2010.06.018.

Danese, A., \& McEwen, B. S. (2012). Adverse childhood experiences, allostasis, allostatic load, and age-related disease. Physiology \& Behavior, 106(1), 29-39. doi:10.1016/j.physbeh.2011.08.019.

DC Baltimore Research Center on Child Health Disparities Writing Group. (2009). Starting early: A life-course perspective on child health disparities Research recommendations. Pediatrics, 124(3), S257S261. doi:10.1542/peds.2009-1100O.

Dearden, L., Sibieta, L., \& Sylva, K. (2011). The socioeconomic gradient in early child outcomes: Evidence from the Millennium Cohort Study. Longitudinal and Life Course Studies, 2, 19-40.

Diez Roux, A. V. (2007). Integrating social and biologic factors in health research: A systems view. Annals of Epidemiology, 17(7), 569-574. doi:10.1016/j. annepidem.2007.03.001.

Diez Roux, A. V. (2011). Complex systems thinking and current impasses in health disparities research. American Journal of Public Health, 101(9), 16271634. doi:10.2105/AJPH.2011.300149.

Dougherty, L. R., Tolep, M. R., Smith, V. C., \& Rose, S. (2013). Early exposure to parental depression and parenting: Associations with young offspring's stress physiology and oppositional behavior. Journal of Abnormal Child Psychology, 41(8), 1299-1310. doi:10.1007/s10802-013-9763-7.

Eisenhower, A., Suyemoto, K., Lucchese, F., \& Canenguez, K. (2014). "Which box should I check?": Examining standard check box approaches to measuring race and ethnicity. Health Services Research, 49(3), 1034-1055. doi:10.1111/1475-6773.12132.

Feinberg, M. E., Jones, D. E., Roettger, M. E., Solmeyer, A., \& Hostetler, M. L. (2014). Long-term follow-up of a randomized trial of family foundations: Effects on children's emotional, behavioral, and school adjustment. Journal of Family Psychology, 28(6), 821-831. doi: $10.1037 /$ fam0000037.

Feinberg, M. E., Roettger, M. E., Jones, D. E., Paul, I. M., \& Kan, M. L. (2015). Effects of a psychosocial couplebased prevention program on adverse birth outcomes. Maternal and Child Health Journal, 19(1), 102-111. doi:10.1007/s10995-014-1500-5.

Flores, G., \& Lin, H. (2013). Trends in racial/ethnic disparities in medical and oral health, access to care, and use of services in US children: Has anything changed over the years? International Journal for Equity in Health, 12, 10. doi:10.1186/1475-9276-12-10.

Flores, G., Olson, L., \& Tomany-Korman, S. C. (2005). Racial and ethnic disparities in early childhood health and health care. Pediatrics, 115(2), e183-e193. doi:10.1542/peds.2004-1474.

Gavin, A. R., Hill, K. G., Hawkins, J. D., \& Maas, C. (2011). The role of maternal early-life and later-life risk factors on offspring low birth weight: Findings from a threegenerational study. The Journal of Adolescent Health, 49(2), 166-171. doi:10.1016/j.jadohealth.2010.11.246.

Gavin, A. R., Thompson, E., Rue, T., \& Guo, Y. (2012). Maternal early life risk factors for offspring birth weight: Findings from the Add Health study. Prevention Science, 13(2), 162-172. doi:10.1007/ s11121-011-0253-2. 
Geronimus, A. T. (1996). Black/white differences in the relationship of maternal age to birthweight: A population-based test of the weathering hypothesis. Social Science \& Medicine, 42(4), 589-597. doi:10.1016/0277-9536(95)00159-X.

Geronimus, A. T. (2013). Deep integration: Letting the epigenome out of the bottle without losing sight of the structural origins of population health. American Journal of Public Health, 103(S1), S56-S63. doi:10.2105/AJPH.2013.301380.

Geronimus, A. T., Hicken, M., Keene, D., \& Bound, J. (2006). "Weathering" and age patterns of allostatic load scores among blacks and whites in the United States. American Journal of Public Health, 96(5), 826-833. doi:10.2105/AJPH.2004.060749.

Geronimus, A. T., Hicken, M. T., Pearson, J. A., Seashols, S. J., Brown, K. L., \& Cruz, T. D. (2010). Do US black women experience stress-related accelerated biological aging? Human Nature, 21(1), 19-38. doi:10.1007/ s12110-010-9078-0.

Gillman, M. W. (2005). Developmental origins of health and disease. The New England Journal of Medicine, 353(17), 1848-1850. doi:10.1056/NEJMe058187.

Gillman, M. W., Rifas-Shiman, S., Berkey, C. S., Field, A. E., \& Colditz, G. A. (2003). Maternal gestational diabetes, birth weight, and adolescent obesity. Pediatrics, 111(3), e221-e226. doi:10.1542/peds.111.3.e221.

Goodman, E., McEwen, B. S., Huang, B., Dolan, L. M., \& Adler, N. E. (2005). Social inequalities in biomarkers of cardiovascular risk in adolescence. Psychosomatic Medicine, 67(1), 9-15. doi:10.1097/01. psy.0000149254.36133.1a.

Goodman, E., Daniels, S. R., \& Dolan, L. M. (2007). Socioeconomic disparities in insulin resistance: Results from the Princeton School District Study. Psychosomatic Medicine, 69(1), 61-67. doi:10.1097/01.psy.0000249732.96753.8f.

Gray, S. C., Edwards, S. E., Schultz, B. D., \& Miranda, M. L. (2014). Assessing the impact of race, social factors and air pollution on birth outcomes: A population-based study. Environmental Health: A Global Access Science Source, 13(1), 4. doi:10.1186/1476-069X-13-4

Gustafsson, P. E., Janlert, U., Theorell, T., Westerlund, H., \& Hammarström, A. (2011). Socioeconomic status over the life course and allostatic load in adulthood: Results from the Northern Swedish Cohort. Journal of Epidemiology and Community Health, 65(11), 986992. doi:10.1136/jech.2010.108332.

Haas, S., \& Rohlfsen, L. (2010). Life course determinants of racial and ethnic disparities in functional health trajectories. Social Science \& Medicine, 70(2), 240-250. doi:10.1016/j.socscimed.2009.10.003.

Hafkamp-de Groen, E., van Rossem, L., de Jongste, J. C., Mohangoo, A. D., Moll, H. A., Jaddoe, V. W. V., et al. (2012). The role of prenatal, perinatal and postnatal factors in the explanation of socioeconomic inequalities in preschool asthma symptoms: The
Generation R Study. Journal of Epidemiology and Community Health, 66(11), 1017-1024. doi:10.1136/ jech-2011-200333.

Hales, C. N., \& Barker, D. J. (2001). The thrifty phenotype hypothesis. British Medical Bulletin, 60, 5-20.

Halfon, N., \& Hochstein, M. (2002). Life course health development: An integrated framework for developing health, policy, and research. Milbank Quarterly, 80(3), 433-479. doi:10.1111/1468-0009.00019.

Halfon, N., Larson, K., Lu, M., Tullis, E., \& Russ, S. (2014a). Lifecourse health development: Past, present and future. Maternal and Child Health Journal, 18(2), 344-365. doi:10.1007/s10995-013-1346-2.

Halfon, N., Long, P., Chang, D. I., Hester, J., Inkelas, M., \& Rodgers, A. (2014b). Applying a 3.0 transformation framework to guide large-scale health system reform. Health Affairs, 33(11), 2003-2011. doi:10.1377/ hlthaff.2014.0485.

Halfon, N., Wise, P. H., \& Forrest, C. B. (2014c). The changing nature of children's health development: New challenges require major policy solutions. Health Affairs, 33(12), 2116-2124. doi:10.1377/ hlthaff.2014.0944.

Halle, T., Forry, N., Hair, E., Perper, K., Wandner, L., Wessel, J., \& Vick, J. (2009). Disparities in early learning and development: Lessons from the Early Childhood Longitudinal Study - Birth Cohort (ECLS-B). Washington, DC: Child Trends.

Hanson, M. A., \& Gluckman, P. D. (2014). Early developmental conditioning of later health and disease: Physiology or pathophysiology? Physiological Reviews, 94(4), 1027-1076. doi:10.1152/ physrev.00029.2013.

Hertzman, C. (2012). Putting the concept of biological embedding in historical perspective. Proceedings of the National Academy of Sciences, 109(2), 1716017167. doi:10.1073/pnas.1202203109.

Hertzman, C., \& Boyce, T. (2010). How experience gets under the skin to create gradients in developmental health. Annual Review of Public Health, 31(1), 329347. doi:10.1146/annurev.publhealth.012809.103538.

Hertzman, C., Power, C., Matthews, S., \& Manor, O. (2001). Using an interactive framework of society and lifecourse to explain self-rated health in early adulthood. Social Science \& Medicine, 53(12), 1575-1585. doi:10.1016/S0277-9536(00)00437-8.

Holzman, C., Eyster, J., Kleyn, M., Messer, L. C., Kaufman, J. S., Laraia, B. A., et al. (2009). Maternal weathering and risk of preterm delivery. American Journal of Public Health, 99(10), 1864-1871. doi:10.2105/AJPH.2008.151589.

Jackson, B., Kubzansky, L. D., Cohen, S., Weiss, S., \& Wright, R. J. (2004). A matter of life and breath: Childhood socioeconomic status is related to young adult pulmonary function in the CARDIA study. International Journal of Epidemiology, 33(2), 271278. doi:10.1093/ije/dyh003. 
Janicki-Deverts, D., Cohen, S., Matthews, K. A., \& Jacobs, D. R. (2012). Sex differences in the association of childhood socioeconomic status with adult blood pressure change: The CARDIA study. Psychosomatic Medicine, 74(7), 728-735. doi:10.1097/PSY.0b013e31825e32e8.

Janus, M., \& Offord, D. R. (2007). Development and psychometric properties of the Early Development Instrument (EDI): A measure of children's school readiness. Canadian Journal of Behavioural Science, 39(1), 1-22. doi:10.1037/cjbs2007001.

Johnson, R. C., \& Schoeni, R. F. (2011). Early-life origins of adult disease: National longitudinal populationbased study of the United States. American Journal of Public Health, 101(12), 2317-2324. doi:10.2105/ AJPH.2011.300252.

Kahn, R. S., Wilson, K., \& Wise, P. H. (2005). Intergenerational health disparities: Socioeconomic status, women's health conditions, and child behavior problems. Public Health Reports, 120(4), 399-408. doi:10.1177/003335490512000407.

Kamphuis, C. B., Turrell, G., Giskes, K., Mackenbach, J. P., \& van Lenthe, F. J. (2012). Socioeconomic inequalities in cardiovascular mortality and the role of childhood socioeconomic conditions and adulthood risk factors: A prospective cohort study with 17-years of follow up. BMC Public Health, 12(1), 1045. doi:10.1186/1471-2458-12-1045.

Khanam, R., Nghiem, H. S., \& Connelly, L. B. (2009). Child health and the income gradient: Evidence from Australia. Journal of Health Economics, 28(4), 805817. doi:10.1016/j.jhealeco.2009.05.001.

Khullar, D., Oreskovic, N. M., Perrin, J. M., \& Goodman, E. (2011). Optimism and the socioeconomic status gradient in adolescent adiposity. The Journal of Adolescent Health, 49(5), 553-555. doi:10.1016/j. jadohealth.2011.04.003.

Kramer, M. R., \& Hogue, C. R. (2009). What causes racial disparities in very preterm birth? A biosocial perspective. Epidemiologic Reviews, 31, 84-98. doi:10.1093/ ajerev/mxp003.

Kramer, M. R., Hogue, C. J., Dunlop, A. L., \& Menon, R. (2011). Preconceptional stress and racial disparities in preterm birth: An overview. Acta Obstetricia Et Gynecologica Scandinavica, 90(12), 1307-1316. doi:10.1111/j.1600-0412.2011.01136.x.

Kuh, D., \& Ben-Shlomo, Y. (Eds.). (2004). A life course approach to chronic disease epidemiology. New York: Oxford University Press.

Lariscy, J. T., Hummer, R. A., \& Hayward, M. D. (2015). Hispanic older adult mortality in the United States: New estimates and an assessment of factors shaping the Hispanic paradox. Demography, 52(1), 1-14. doi:10.1007/s13524-014-0357-y.

Larson, K., \& Halfon, N. (2009). Family income gradients in the health and health care access of US children. Maternal and Child Health Journal, 14(3), 332-342. doi:10.1007/s10995-009-0477-y.
Larson, K., Russ, S. A., Nelson, B. B., Olson, L. M., \& Halfon, N. (2015). Cognitive ability at kindergarten entry and socioeconomic status. Pediatrics, 135(2), e440-e448. doi:10.1542/peds.2014-0434.

Laubenthal, J., Zlobinskaya, O., Poterlowicz, K., Baumgartner, A., Gdula, M. R., Fthenou, E., et al. (2012). Cigarette smoke-induced transgenerational alterations in genome stability in cord blood of human F1 offspring. The FASEB Journal, 26(10), 3946-3956. doi:10.1096/fj.11-201194.

Leventhal, T., \& Dupéré, V. (2011). Moving to opportunity: Does long-term exposure to "low-poverty" neighborhoods make a difference for adolescents? Social Science \& Medicine, 73(5), 737-743. doi:10.1016/j. socscimed.2011.06.042.

Livingood, W. C., Brady, C., Pierce, K., Atrash, H., Hou, T., \& Bryant, T. (2010). Impact of pre-conception health care: Evaluation of a social determinants focused intervention. Maternal and Child Health Journal, 14(3), 382-391. doi:10.1007/s10995-009-0471-4.

Love, C., David, R. J., Rankin, K. M., \& Collins, J. W. (2010). Exploring weathering: Effects of lifelong economic environment and maternal age on low birth weight, small for gestational age, and preterm birth in African-American and white women. American Journal of Epidemiology, 127-134. doi:10.1093/aje/ kwq109.

Lu, M. C. (2014). Improving maternal and child health across the life course: Where do we go from here? Maternal and Child Health Journal, 18(2), 339-343. doi:10.1007/s10995-013-1400-0.

Ludwig, J., Duncan, G. J., Gennetian, L. A., Katz, L. F., Kessler, R. C., Kling, J. R., \& Sanbonmatsu, L. (2013). Long-term neighborhood effects on low-income families: Evidence from Moving to Opportunity. The American Economic Review, 103(3), 226-231. doi:10.1257/aer.103.3.226.

Luo, Y., \& Waite, L. J. (2005). The impact of childhood and adult SES on physical, mental, and cognitive wellbeing in later life. The Journals of Gerontology Series B: Psychological Sciences and Social Sciences, 60(2), S93-S101. doi:10.1093/geronb/60.2.S93.

Martin, J. A., Hamiltion, B. E., Osterman, M. J. K., Curtin, S. C., \& Mathews, T. J. (2015). Births: Final data for 2013. National Vital Statistics Reports, 64(1), $1-65$.

Martinson, M. L., McLanahan, S., \& Brooks-Gunn, J. (2015). Variation in child body mass index patterns by race/ethnicity and maternal nativity status in the United States and England. Maternal and Child Health Journal, 19(2), 373-380. doi:10.1007/ s10995-014-1519-7.

McEwen, B. S. (2015). Biomarkers for assessing population and individual health and disease related to stress and adaptation. Metabolism, 64(3 Suppl 1), S2-S10. doi:10.1016/j.metabol.2014.10.029.

Meaney, M. J. (2010). Epigenetics and the biological definition of gene $\mathrm{x}$ environment interactions. 
Child Development, 81(1), 41-79. doi:10.1111/j. 1467-8624.2009.01381.x.

Meloni, M. (2014). The social brain meets the reactive genome: Neuroscience, epigenetics and the new social biology. Frontiers in Human Neuroscience, 8, 309. doi:10.3389/fnhum.2014.00309.

Mersha, T. B., \& Abebe, T. (2015). Self-reported race/ ethnicity in the age of genomic research: Its potential impact on understanding health disparities. Human Genomics, 9(1), 1. doi:10.1186/s40246-014-0023-x.

Miller, G. E., \& Chen, E. (2007). Unfavorable socioeconomic conditions in early life presage expression of proinflammatory phenotype in adolescence. Psychosomatic Medicine, 69(5), 402-409. doi:10.1097/PSY.0b013e318068fcf9.

Miller, G. E., \& Chen, E. (2013). The biological residue of childhood poverty. Child Development Perspectives, 7(2), 67-73. doi:10.1111/cdep.12021.

Miller, G. E., Lachman, M. E., Chen, E., Gruenewald, T. L., Karlamangla, A. S., \& Seeman, T. E. (2011). Pathways to resilience: Maternal nurturance as a buffer against the effects of childhood poverty on metabolic syndrome at midlife. Psychological Science, 22(12), 1591-1599. doi:10.1177/0956797611419170.

Miller, G. E., Brody, G. H., Yu, T., \& Chen, E. (2014). A family-oriented psychosocial intervention reduces inflammation in low-SES African American youth. Proceedings of the National Academy of Sciences, 111(31), 11287-11292. doi:10.1073/ pnas. 1406578111 .

Miranda, M. L., Swamy, G. K., Edwards, S., Maxson, P., Gelfand, A., \& James, S. (2010). Disparities in maternal hypertension and pregnancy outcomes: Evidence from North Carolina, 19942003. Public Health Reports, 125(4), 579-587. doi:10.1177/003335491012500413.

Misteli, T. (2013). The cell biology of genomes: Bringing the double helix to life. Cell, 152(6), 1209-1212. doi:10.1016/j.cell.2013.02.048.

National Research Council \& Institute of Medicine, Committee on Evaluation of Children's Health, Board on Children, Youth, \& Families, Division of Behavioral \& Social Sciences \& Education. (2004). Children's health, the nation's wealth: Assessing and improving child health. Washington, DC: The National Academies Press.

Oberlander, T. F., Weinberg, J., Papsdorf, M., Grunau, R., Misri, S., \& Devlin, A. M. (2008). Prenatal exposure to maternal depression, neonatal methylation of human glucocorticoid receptor gene (NR3C1) and infant cortisol stress responses. Epigenetics, 3(2), 97-106. doi:10.4161/epi.3.2.6034.

Olds, D. L., Henderson, C. R., Cole, R., Eckenrode, J., Kitzman, H., Luckey, D., et al. (1998). Long-term effects of nurse home visitation on children's criminal and antisocial behavior: 15-year follow-up of a randomized controlled trial. JAMA, 280(14), 1238-1244. doi:10.1001/jama.280.14.1238.
Olds, D. L., Kitzman, H., Cole, R., Robinson, J., Sidora, K., Luckey, D. W., et al. (2004). Effects of nurse home-visiting on maternal life course and child development: Age 6 follow-up results of a randomized trial. Pediatrics, 114(6), 1550-1559. doi:10.1542/ peds.2004-0962.

Olds, D. L., Kitzman, H., Hanks, C., Cole, R., Anson, E., Sidora-Arcoleo, K., et al. (2007). Effects of nurse home visiting on maternal and child functioning: Age 9 follow-up of a randomized trial. Pediatrics, 120(4), e832-e845. doi:10.1542/peds.2006-2111.

Overton, W. F. (2013a). A new paradigm for developmental science: Relationism and relational-developmental systems. Applied Developmental Science, 17(2), 94-107. doi:10.1080/10888691.2013.778717.

Overton, W. F. (2013b). Relationism and relational developmental systems: A paradigm for developmental science in the post-Cartesian era. Advances in Child Development and Behavior, 44, 21-64.

Overton, W. F. (2014). Relational developmental systems and developmental science: A focus on methodology. In P. C. M. Molenaar \& R. M. Lerner (Eds.), Handbook of developmental systems theory and methodology (pp. 19-65). New York: The Guilford Press.

Packard, C. J., Bezlyak, V., McLean, J. S., Batty, G. D., Ford, I., Burns, H., et al. (2011). Early life socioeconomic adversity is associated in adult life with chronic inflammation, carotid atherosclerosis, poorer lung function and decreased cognitive performance: A cross-sectional, population-based study. BMC Public Health, 11, 42. doi:10.1186/1471-2458-11-42.

Pais, J. (2014). Cumulative structural disadvantage and racial health disparities: The pathways of childhood socioeconomic influence. Demography, 51(5), 17291753. doi:10.1007/s13524-014-0330-9.

Palfrey, J. S., Hauser-Cram, P., Bronson, M. B., Warfield, M. E., Sirin, S., \& Chan, E. (2005). The Brookline Early Education Project: A 25 year follow-up study of a family-centered early health and development intervention. Pediatrics, 116(1), 144-152. doi:10.1542/ peds.2004-2515.

Perroud, N., Dayer, A., Piguet, C., Nallet, A., Favre, S., Malafosse, A., \& Aubry, J. (2014). Childhood maltreatment and methylation of the glucocorticoid receptor gene NR3C1 in bipolar disorder. The British Journal of Psychiatry: The Journal of Mental Science, 204(1), 30-35. doi:10.1192/bjp.bp.112.120055.

Pietras, S. A., \& Goodman, E. (2013). Socioeconomic status gradients in inflammation in adolescence. Psychosomatic Medicine, 75(5), 442-448. doi:10.1097/PSY.0b013e31828b871a.

Propper, C., Rigg, J., \& Burgess, S. (2007). Child health: Evidence on the roles of family income and maternal mental health from a UK birth cohort. Health Economics, 16(11), 1245-1269. doi:10.1002/hec.1221.

Pudrovska, T., Logan, E. S., \& Richman, A. (2014). Earlylife social origins of later-life body weight: The role of socioeconomic status and health behaviors over 
the life course. Social Science Research, 46, 59-71. doi:10.1016/j.ssresearch.2014.02.007.

Reynolds, A. J., Temple, J. A., Ou, S., Robertson, D., Mersky, J., Topitzea, J., \& Niles, M. D. (2007). Effects of a school-based, early childhood intervention on adult health and well-being: A 19-year follow-up of low-income families. Archives of Pediatrics \& Adolescent Medicine, 161(8), 730-739. doi:10.1001/ archpedi.161.8.730.

Reynolds, A. J., Temple, J. A., Ou, S., Arteaga, I. A., \& White, B. A. B. (2011). School-based early childhood education and age-28 well-being: Effects by timing, dosage, and subgroups. Science, 333(6040), 360-364. doi:10.1126/science.1203618.

Robertson, T., Batty, G. D., Der, G., Green, M. J., McGlynn, L. M., McIntyre, A., et al. (2012). Is telomere length socially patterned? Evidence from the West of Scotland Twenty-07 Study. PLOS ONE, 7(7), e41805. doi:10.1371/journal.pone.0041805.

Romens, S. E., McDonald, J., Svaren, J., \& Pollak, S. D. (2014). Associations between early life stress and gene methylation in children. Child Development. doi:10.1111/cdev.12270.

Sacker, A., Worts, D., \& McDonough, P. (2011). Social influences on trajectories of self-rated health: Evidence from Britain, Germany, Denmark and the USA. Journal of Epidemiology and Community Health, 65(2), 130-136. doi:10.1136/jech.2009.091199.

Sauvé, B., Koren, G., Walsh, G., Tokmakejian, S., \& Uum, S. H. V. (2007). Measurement of cortisol in human hair as a biomarker of systemic exposure. Clinical \& Investigative Medicine, 30(5), 183-191. doi:10.25011/ cim.v30i5.2894.

Schonert-Reichl, K. A., Guhn, M., Gadermann, A. M., Hymel, S., Sweiss, L., \& Hertzman, C. (2013). Development and validation of the Middle Years Development Instrument (MDI): Assessing children's well-being and assets across multiple contexts. Social Indicators Research, 114, 345-369. doi:10.1007/ s11205-012-0149-y.

Schoon, I., Sacker, A., \& Bartley, M. (2003). Socioeconomic adversity and psychosocial adjustment: A developmental-contextual perspective. Social Science \& Medicine, 57(6), 1001-1015. doi:10.1016/ S0277-9536(02)00475-6.

Schweinhart, L. J., \& Weikart, D. P. (1993). Success by empowerment: The High/Scope Perry Preschool Study through age 27. Young Children, 49(1), 54-58.

Schweinhart, L. J., Montie, J., Xiang, Z., Barnett, W. S., Belfield, C. R., \& Nores, M. (2005). Lifetime effects: The High/Scope Perry Preschool study through age 40. Yipsilanti: High/Scope Press.

Seeman, T., Epel, E., Gruenewald, T., Karlamangla, A., \& McEwen, B. S. (2010). Socio-economic differentials in peripheral biology: Cumulative allostatic load. Annals of the New York Academy of Sciences, 1186, 223-239. doi:10.1111/j.1749-6632.2009.05341.x.
Shapira, N. (2008). Prenatal nutrition: A critical window of opportunity for mother and child. Women's Health, 4(6), 639-656. doi:10.2217/17455057.4.6.639.

Sheridan, M. A., Sarsour, K., Jutte, D., D’Esposito, M., $\&$ Boyce, T. W. (2012). The impact of social disparity on prefrontal function in childhood. PLOS ONE, 7(4), e35744. doi:10.1371/journal.pone.0035744.

Singh, G. K., \& Hiatt, R. A. (2006). Trends and disparities in socioeconomic and behavioural characteristics, life expectancy, and cause-specific mortality of nativeborn and foreign-born populations in the United States, 1979-2003. International Journal of Epidemiology, 35(4), 903-919. doi:10.1093/ije/dyl089.

Singh, G. K., \& Kogan, M. D. (2007). Widening socioeconomic disparities in US childhood mortality, 19692000. American Journal of Public Health, 97(9), 1658-1665. doi:10.2105/AJPH.2006.087320.

Singh, G. K., \& Siahpush, M. (2002). Increasing inequalities in all-cause and cardiovascular mortality among US adults aged 25-64 years by area socioeconomic status, 1969-1998. International Journal of Epidemiology, 31(3), 600-613.

Speybroeck, N., Van Malderen, C., Harper, S., Müller, B., \& Devleesschauwer, B. (2013). Simulation models for socioeconomic inequalities in health: A systematic review. International Journal of Environmental Research and Public Health, 10(11), 5750-5780. doi:10.3390/ijerph10115750.

Sternthal, M. J., Coull, B. A., Chiu, Y. M., Cohen, S., \& Wright, R. J. (2011). Associations among maternal childhood socioeconomic status, cord blood IgE levels, and repeated wheeze in urban children. The Journal of Allergy and Clinical Immunology, 128(2), 337-345. e1. doi:10.1016/j.jaci.2011.05.008.

Strand, B. H., Cooper, R., Hardy, R., Kuh, D., \& Guralnik, J. (2011). Lifelong socioeconomic position and physical performance in midlife: Results from the British 1946 birth cohort. European Journal of Epidemiology, 26(6), 475-483. doi:10.1007/ s10654-011-9562-9.

Tanner, V. (Ed.). (2015). Health disparities and inequalities in the United States: Selected reports. New York: Nova Science Publishers Inc..

Tehranifar, P., Wu, H., Fan, X., Flom, J. D., Ferris, J. S., Cho, Y. H., et al. (2013). Early life socioeconomic factors and genomic DNA methylation in mid-life. Epigenetics, 8(1), 23-27. doi:10.4161/epi.22989.

Thayer, Z. M., \& Kuzawa, C. W. (2011). Biological memories of past environments: Epigenetic pathways to health disparities. Epigenetics, 6(7), 798-803. doi:10.4161/epi.6.7.16222.

Van de Mheen, H., Stronks, K., Looman, C. W. N., \& Mackenbach, J. P. (1998). Does childhood socioeconomic status influence adult health through behavioural factors? International Journal of Epidemiology, 27(3), 431-437. doi:10.1093/ije/27.3.431.

Violato, M., Petrou, S., \& Gray, R. (2009). The relationship between household income and childhood 
respiratory health in the United Kingdom. Social Science \& Medicine, 69(6), 955-963. doi:10.1016/j. socscimed.2009.06.036.

Wadsworth, M. E. (1997). Health inequalities in the life course perspective. Social Science \& Medicine, 44(6), 859-869.
Warner, D. F., \& Hayward, M. D. (2006). Early-life origins of the race gap in men's mortality. Journal of Health and Social Behavior, 47(3), 209-226. doi:10.1177/002214650604700302.

Open Access This chapter is licensed under the terms of the Creative Commons Attribution 4.0 International License (http://creativecommons.org/licenses/by/4.0/), which permits use, sharing, adaptation, distribution and reproduction in any medium or format, as long as you give appropriate credit to the original author(s) and the source, provide a link to the Creative Commons license and indicate if changes were made.

The images or other third party material in this chapter are included in the chapter's Creative Commons license, unless indicated otherwise in a credit line to the material. If material is not included in the chapter's Creative Commons license and your intended use is not permitted by statutory regulation or exceeds the permitted use, you will need to obtain permission directly from the copyright holder. 